\title{
FDG positron emission tomography/computed tomography findings for the prediction of early recurrence of hepatocellular carcinoma after surgical resection
}

\author{
ATSUSHI HIRAOKA ${ }^{1}$, HIRONORI OCHI $^{1}$, SATOSHI HIDAKA ${ }^{1}$, TAKAHIDE UEHARA ${ }^{1}$, AKI HASEBE $^{1}$, \\ TETSUYA TANIHIRA ${ }^{1}$, YASUNAO MIYAMOTO ${ }^{1}$, TOMOYUKI NINOMIYA ${ }^{1}$, HIDEKI KAWASAKI ${ }^{2}$, \\ ICHIRO SOGABE ${ }^{3}$, YOSHIHIRO ISHIMARU ${ }^{3}$, MASAO MIYAGAWA $^{3}$, KEIZO FURUYA $^{4}$, MASASHI HIROOKA ${ }^{5}$, \\ MASANORI ABE ${ }^{5}$, YOICHI HIASA ${ }^{5}$, BUNZO MATSUURA ${ }^{5}$, MORIKAZU ONJI ${ }^{5}$ and KOJIRO MICHITAKA ${ }^{1}$ \\ ${ }^{1}$ Gastroenterology Center; Departments of ${ }^{2}$ Surgery, ${ }^{3}$ Radiology, and ${ }^{4}$ Pathology, Ehime Prefectural Central Hospital; \\ ${ }^{5}$ Department of Gastroenterology and Metabology, Ehime University Graduate School of Medicine, Ehime, Japan
}

Received May 13,2010; Accepted June 29, 2010

DOI: $10.3892 / \mathrm{etm} .2010 .126$

\begin{abstract}
We investigated the predictive value of fluorine-18fluorodenoxyglucose positron emission tomography/computed tomography for pathological malignant potential and early recurrence of hepatocellular carcinoma (HCC) after resection. From April 2006 to October 2009, 53 patients with naïve HCC were enrolled. Accumulations of 2-[18F]-fluoro-2-deoxy-Dglucose (FDG) standardized uptake value (SUVmax) in both $\mathrm{HCC}$ and non-HCC areas of the liver as well as the ratio of SUVmax (R-SUV; HCC/liver) were calculated. The results were evaluated to determine prognostic factors for early recurrence. One patient was graded as tumor node metastasis stage I, 35 as II, 14 as III and 3 as stage IV. Elevated protein induced by vitamin $\mathrm{K}$ absence or antagonist II ( $\geq 200 \mathrm{mAU} / \mathrm{ml})$ as well as elevated fucosylated $\alpha$-fetoprotein $(\geq 15 \%)$, tumor size $(\geq 5 \mathrm{~cm})$ and high R-SUV ( $\geq 1.5$ ) were risk factors for early recurrence in a univariate analysis $(\mathrm{P}<0.05)$. In a multivariate analysis, high R-SUV $(\geq 1.5)$ was the only risk factor $(\mathrm{P}<0.05)$. The recurrence-free rate in patients with low R-SUV $(<1.5, n=34)$ was higher than that in those with high R-SUV $(\geq 1.5, n=19)$ (1- and 2-year rates: 100 and 67\%, 67 and 17\%; respectively, $\mathrm{P}<0.01)$. Patients with Edmondson III showed higher R-SUV values than those with Edmondson I and II $(3.0 \pm 1.8,1.4 \pm 0.3$ and $1.9 \pm 0.9$, respectively, $\mathrm{P}<0.01)$, while those with microvascular invasion (vp)(+), micro-intrahepatic metastasis (im) (+) or non-boundary type showed higher R-SUV values than $\mathrm{vp}(-), \mathrm{im}(-)$ and boundary type $(3.6 \pm 2.4$ vs. $2.0 \pm 0.9,3.5 \pm 2.3$ vs. $1.9 \pm 0.8$ and $2.9 \pm 1.8$ vs. $1.6 \pm 0.5$, respectively, $\mathrm{P}<0.01)$.
\end{abstract}

Correspondence to: Atsushi Hiraoka, Gastroenterology Center, Ehime Prefectural Central Hospital, Kasuga-Cho 83, Matsuyama, Ehime 790-0024, Japan

E-mail: hirage@m.ehime-u.ac.jp

Key words: 2-[18F]-fluoro-2-deoxy-D-glucose, positron emission tomography, computed tomography, hepatocellular carcinoma, prognosis, hepatic resection, recurrence
R-SUV is proposed to be a useful marker for the prediction of early recurrence of $\mathrm{HCC}$ after resection.

\section{Introduction}

Recently, 2-[18F]-fluoro-2-deoxy-D-glucose (FDG) positron emission tomography (PET)/computed tomography (CT) has been used for diagnosing malignant tumors, and many reports have described its role for predicting the malignant potential of these tumors. However, the clinical efficacy of PET/CT for diagnosing hepatocellular carcinoma (HCC) remains controversial, and only a few reports have described the predictive value of its findings for pathological malignant potential and prognosis (1-3).

Hepatic resection is performed as a standard therapy for HCC in Japan (4,5). However, recurrence of HCC after resection is known to occur at a high rate, and early recurrence is considered to be a significant prognostic factor for death. Although macroinvasion of HCC to the portal vein is also a factor for poor prognosis (6), most patients with HCC without macro-tumor thrombosis suffer from recurrence after resection. Previous reports have investigated prognostic markers for early recurrence and survival, including the doubling time of pre-operative serum $\alpha$-fetoprotein (AFP) and protein induced by vitamin $\mathrm{K}$ absence or antagonist II (PIVKA-II) (7), complication with diabetes mellitus (8), hepatic steatosis (9) and tumor node metastasis (TNM) stage (10), although these are not adequately sensitive. In the present study, we investigated the predictive value of PET/CT for the pathological malignant potential of HCC as a new indicator for early recurrence after hepatic resection.

\section{Materials and methods}

From April 2006 to October 2009, 53 patients with naïve HCC, examined by PET/CT and treated by hepatic resection, were enrolled. None had poorly controlled diabetes mellitus. All were examined using PET/CT (Discovery ST Elite 16; GE Healthcare Japan Co. Ltd., Tokyo, Japan) within the month 
Table I. Univariate analysis of clinical parameters for early recurrence after resection.

\begin{tabular}{llccr}
\hline Factors & No. & Hazard ratio & $95 \%$ CI & P-value \\
\hline Age in years $(<70: \geq 70)$ & $23: 30$ & 0.662 & $0.234-1.873$ & 0.437 \\
Anti-HCV (positive:negative) & $28: 25$ & 0.612 & $0.221-1.674$ & 0.345 \\
Gender (male:female) & $40: 13$ & 0.688 & $0.189-2.507$ & 0.571 \\
Aspartate transferase $(\mathrm{IU} / \mathrm{ll})(<80: \geq 80)$ & $44: 9$ & 2.501 & $0.841-7.437$ & 0.099 \\
Alanine transferase $(\mathrm{IU} / \mathrm{l})(<80: \geq 80)$ & $48: 5$ & 3.710 & $0.956-14.402$ & 0.058 \\
Total bilirubin $(\mathrm{mg} / \mathrm{dl})(<2: \geq 2)$ & $52: 1$ & 0.048 & $0.000-2.823$ & 0.810 \\
Albumin $(\mathrm{g} / \mathrm{dl})(<3.5: \geq 3.5)$ & $11: 42$ & 1.456 & $0.307-6.904$ & 0.636 \\
Prothrombin time $(\%)(<80: \geq 80)$ & $25: 28$ & 0.923 & $0.341-2.493$ & 0.874 \\
Platelets $\left(\mathrm{x} 10^{4}\right.$ cells/ $\left.\mu 1\right)(<12: \geq 12)$ & $18: 35$ & 1.453 & $0.515-4.098$ & 0.480 \\
Child-Pugh $(\mathrm{A}: \mathrm{B})$ & $44: 9$ & 1.679 & $0.352-8.003$ & 0.515 \\
AFP $(\mathrm{ng} / \mathrm{ml})(<100: \geq 100)$ & $41: 12$ & 1.996 & $0.619-6.441$ & 0.248 \\
AFP-L3 $(\%)(<15: \geq 15)$ & $38: 15$ & 3.165 & $1.101-9.095$ & 0.032 \\
PIVKA-II $(\mathrm{mAU} / \mathrm{ml})(<200: \geq 200)$ & $31: 22$ & 3.805 & $1.285-11.267$ & 0.016 \\
Diabetes mellitus $($ positive:negative $)$ & $16: 37$ & 0.371 & $0.102-1.354$ & 0.133 \\
No. of HCC $(\mathrm{multiple}: \mathrm{single})$ & $15: 38$ & 1.578 & $0.540-4.607$ & 0.404 \\
Tumor size $(<5 \mathrm{~cm}: \geq 5 \mathrm{~cm})$ & $31: 22$ & 3.050 & $1.036-8.983$ & 0.043 \\
R-SUV $(<1.5: \geq 1.5)$ & $19: 34$ & 10.581 & $1.394-80.343$ & 0.023 \\
\hline
\end{tabular}

CI, confidence interval; HCV, hepatitis C virus; AFP, $\alpha$-fetoprotein; AFP-L3, fucosylated AFP; PIVKA-II, protein induced by vitamin K absence or antagonist II; TNM stage, tumor node metastasis stage; R-SUV, ratio of accumulations of FDG in HCC and non-HCC areas of the liver.

prior to resection. PET/CT was performed 60 min after a bolus injection of F-18 FDG (3 MBGq/kg). Accumulations of FDG [standardized uptake value (SUVmax)] in HCC and non-HCC areas of the liver as well as the ratio of SUVmax (R-SUV), which indicated the tumor to non-tumor ratio, were determined. In cases with multiple HCC, the SUVmax was calculated for the main nodule. From these findings, we evaluated prognostic factors for early recurrence, which was defined as recurrence within 2 years of resection. Moreover, R-SUV values were compared to the pathological findings, including microvascular invasion (vp), micro-intrahepatic metastasis (im) and gross type of HCC $(11,12)$. The patients were divided into two groups, low R-SUV ( $n=19)$ and high R-SUV ( $n=34)$, and their clinical parameters were compared.

Statistical analysis. Data are expressed as the mean \pm standard deviation (SD). Statistical analyses were performed using the Student's t-test for unpaired data, a $\chi^{2}$ test, Fischer's exact test, a Mann-Whitney U test and a log-rank test, as appropriate. All statistical analyses were performed with SPSS 16.0J (SPSS Japan Inc., Tokyo, Japan). A P-value of $<0.05$ was considered to represent statistical significance.

\section{Results}

One patient was classified as TNM stage I, 35 as stage II, 14 as stage III and 3 as stage IV, based on the results of imaging examinations (abdominal ultrasonography and dynamic CT). There were no cases with extrahepatic metastasis. R-SUV values ranged from 1.0 to 6.9. In pathological analyses, all were diagnosed as typical HCC. PIVKA-II ( $\geq 200 \mathrm{mAU} / \mathrm{ml})$, fucosylated AFP (AFP-L3) $(\geq 15 \%)$, tumor size $(\geq 5 \mathrm{~cm})$ and high
Table II. Multivariate analysis of clinical parameters for early recurrence after resection.

\begin{tabular}{lccc}
\hline Factors & Hazard ratio & $95 \%$ CI & P-value \\
\hline AFP-L3 $(\geq 15 \%)$ & 1.644 & $0.510-5.308$ & 0.405 \\
PIVKA-II $(\geq 200 \mathrm{mAU} / \mathrm{ml})$ & 2.113 & $0.481-9.275$ & 0.322 \\
Tumor size $(\geq 5 \mathrm{~cm})$ & 1.157 & $0.271-4.935$ & 0.843 \\
R-SUV $(\geq 1.5)$ & 8.137 & $1.027-64.466$ & 0.047 \\
\hline
\end{tabular}

CI, confidence interval; AFP-L3, fucosylated $\alpha$-fetoprotein; PIVKA-II, protein induced by vitamin $\mathrm{K}$ absence or antagonist II; R-SUV, ratio of accumulations of FDG in HCC and non-HCC areas of the liver.

R-SUV ( $\geq 1.5)$ were found to be risk factors for early recurrence in a univariate analysis $(\mathrm{P}<0.05$, respectively) (Table I). In a multivariate analysis, high R-SUV $(\geq 1.5)$ was the only risk factor $(\mathrm{P}<0.05)$ (Table II). The recurrence-free rate in the low R-SUV group was higher than that in the high R-SUV group (1- and 2-year recurrence-free rates: 100 and 67\%, 67 and $17 \%$, respectively; $\mathrm{P}<0.01$ ) (Fig. 1). While the frequencies of high levels of PIVKA-II ( $\geq 200 \mathrm{mAU} / \mathrm{ml})$ and AFP-L3 $(\geq 15 \%)$ were greater in the high R-SUV group (52.9 and 38.2\% vs. 21.1 and $10.5 \%$, respectively; $\mathrm{P}<0.01$ ), there were no significant differences in regard to the frequencies of high levels of AFP ( $\geq 100 \mathrm{ng} / \mathrm{ml}$ ), tumor diameter $\geq 5 \mathrm{~cm}$, Child-Pugh class, number of tumors and TNM stage between the groups (Table III).

Patients with HCC nodules rated as Edmondson III (13) had a higher R-SUV value $(3.0 \pm 1.8)$ than those rated as I 
Table III. Clinical background of the patients.

\begin{tabular}{|c|c|c|c|}
\hline & Low R-SUV group (n=19) & High R-SUV group (n=34) & P-value \\
\hline Age (years) & $68.2 \pm 14.1$ & $69.5 \pm 10.5$ & 0.705 \\
\hline Anti-HCV (positive:negative) & $13: 6$ & $15: 19$ & 0.092 \\
\hline Gender (male:female) & $15: 4$ & $25: 9$ & 0.705 \\
\hline Aspartate transferase (IU/l) & $49.4 \pm 32.2$ & $50.2 \pm 25.8$ & 0.308 \\
\hline Alanine transferase (IU/l) & $40.5 \pm 25.4$ & $41.5 \pm 27.8$ & 0.934 \\
\hline Total bilirubin (mg/dl) & $0.79 \pm 0.49$ & $0.66 \pm 0.28$ & 0.085 \\
\hline Albumin (g/dl) & $4.0 \pm 0.6$ & $4.0 \pm 0.5$ & 0.555 \\
\hline Prothrombin time $(\%)$ & $80.1 \pm 12.2$ & $81.2 \pm 9.9$ & 0.127 \\
\hline Platelets (x10 ${ }^{4}$ cells $\left./ \mu 1\right)$ & $13.0 \pm 4.7$ & $16.0 \pm 5.7$ & 0.696 \\
\hline Child-Pugh class (A:B) & $15: 4$ & $29: 5$ & 0.528 \\
\hline $\operatorname{AFP}(n g / m l)$ & $371.2 \pm 1,199.4$ & $2,306.5 \pm 12,657.9$ & 0.201 \\
\hline AFP-L3 (\%) & $1.6 \pm 5.1$ & $16.9 \pm 23.9$ & $<0.001$ \\
\hline PIVKA-II (mAU/ml) & $424.4 \pm 1,123.6$ & $8,436.2 \pm 17,683.6$ & 0.001 \\
\hline Tumor size $(<5 \mathrm{~cm}: \geq 5 \mathrm{~cm})$ & $14: 5$ & $17: 17$ & 0.077 \\
\hline No. of tumors & $1.4 \pm 0.7$ & $1.4 \pm 0.7$ & 0.819 \\
\hline Score of up to 7 criteria & $5.0 \pm 1.7$ & $7.4 \pm 3.4$ & 0.013 \\
\hline TNM stage (I:II:III:IV) & $1: 13: 5: 0$ & $0: 22: 9: 3$ & 0.320 \\
\hline Mean R-SUV & $1.23 \pm 1.45$ & $2.73 \pm 1.65$ & $<0.001$ \\
\hline
\end{tabular}

HCV, hepatitis C virus; AFP, $\alpha$-fetoprotein; AFP-L3, fucosylated AFP; PIVKA-II, protein induced by vitamin K absence or antagonist II; TNM stage, tumor node metastasis stage; R-SUV, ratio of accumulations of FDG in HCC and non-HCC areas of the liver.

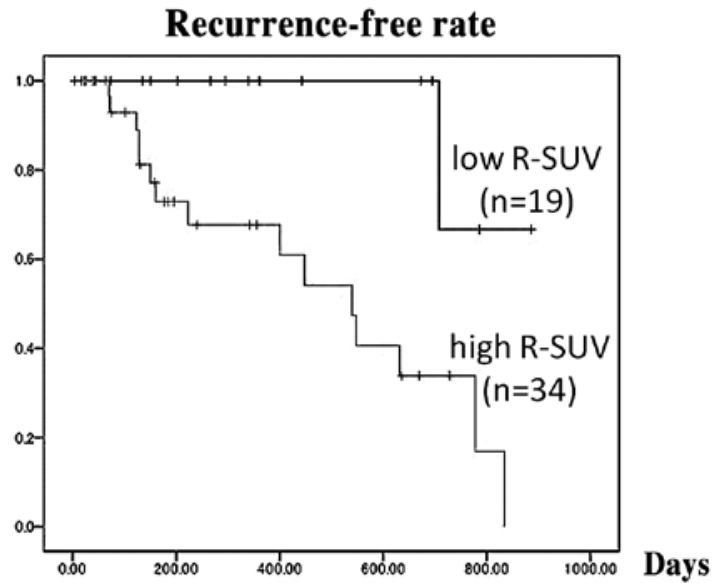

Figure 1. Recurrence rates in both patient groups. A higher level of early recurrence after resection was observed in the high R-SUV group $(\mathrm{P}<0.01)$.

and II $(1.4 \pm 0.3$ and $1.9 \pm 0.9$, respectively; $\mathrm{P}<0.01)$. Patients with nodules showing $\mathrm{vp}(+)$ and $\mathrm{im}(+)$, and with non-boundary type of nodules (single nodular type with extranodular growth, confluent multinodular or invasive type) had higher R-SUV values than those with $\mathrm{vp}(-), \mathrm{im}(-)$ or boundary type (vaguely nodular or single nodular type) $(3.6 \pm 2.4$ vs. $2.0 \pm 0.9,3.5 \pm 2.3$ vs. $1.9 \pm 0.8$ and $2.9 \pm 1.8$ vs. $1.6 \pm 0.5$, respectively; $\mathrm{P}<0.01)$. Throughout the observation period, extrahepatic metastasis was observed in 2 cases of stage II; these cases had high R-SUV (2.3 and 2.4, respectively). Fig. 2 shows representative results of a patient with low R-SUV (1.4) whose pathological findings were single nodular type, Edmondson I, and who
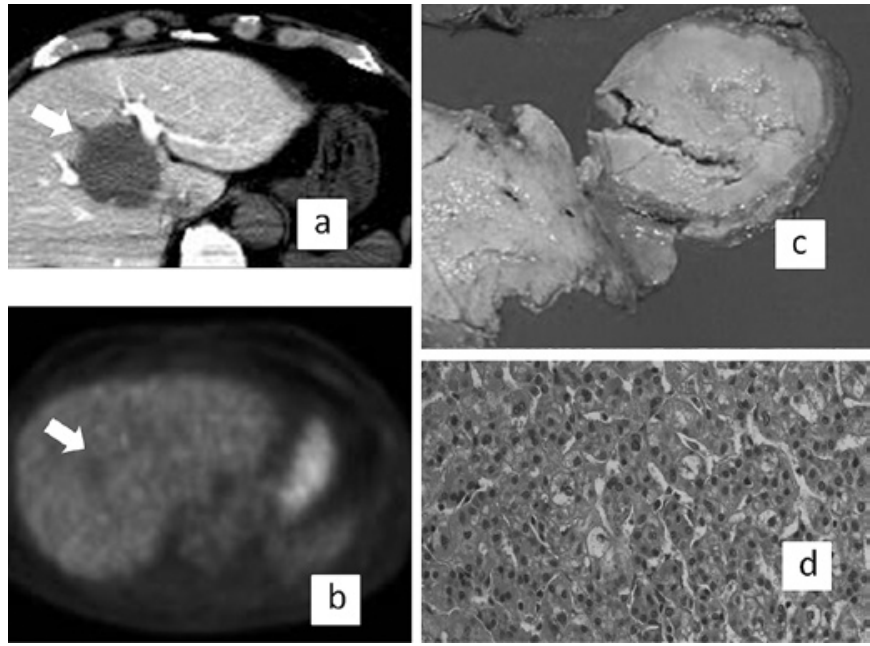

Figure 2. Accumulations of FDG (SUV) in both the HCC and non-HCC areas of the liver. The ratio (R-SUV) was calculated using FDG PET/CT findings. Representative case with HCC in the 4th segment of the liver (5.1 cm in diameter). (a) The tumor is observable as a defect in the CT arterial portography findings. (b) A low R-SUV value (1.4) was revealed by FDG PET/CT. (c) Resected specimen showing the tumor as a single nodular type. (d) The tumor was diagnosed as a well-differentiated HCC (Edmondson I) from the histological findings.

was negative for both vp and im. By contrast, Fig. 3 presents the results of a representative patient with high R-SUV (1.9) whose pathological findings were confluent multinodular type, Edmondson III and positive for vp, though the tumor size was small (2.5 $\mathrm{cm}$ in diameter). 


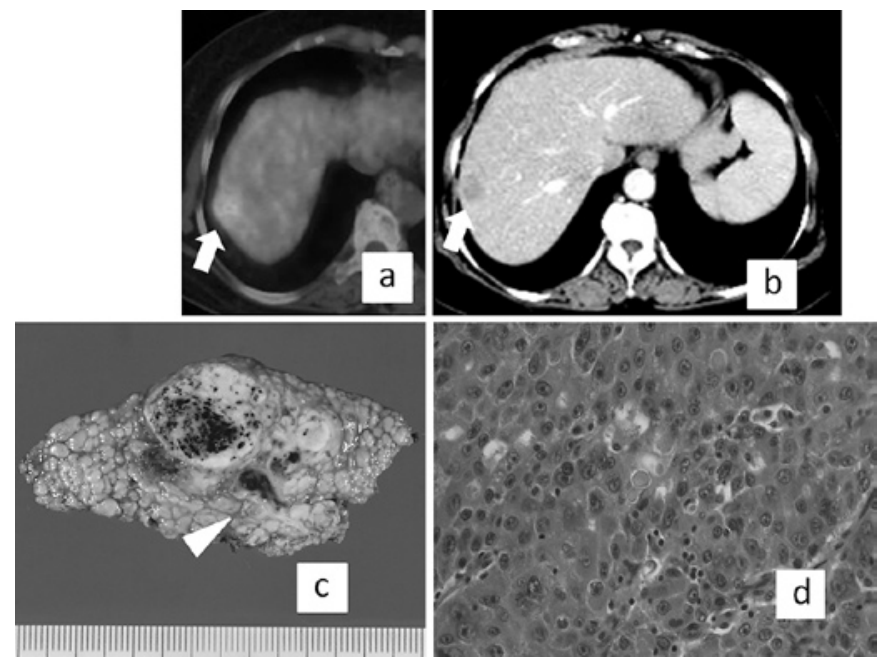

Figure 3. Representative case with HCC in the 8th segment of the liver ( $2.5 \mathrm{~cm}$ in diameter). (a) The tumor is noted as a defect in the CT arterial portography findings. (b) The tumor had a high R-SUV value (1.9) as shown by FDG PET/CT. (c) Resected specimen showing the tumor as a confluent multinodular type with macroinvasion to the 8th portal vein (arrowhead) Invasion of the portal vein was not detected in an imaging examination conducted 2 weeks before surgical resection. (d) The tumor was diagnosed as a poorly differentiated HCC (Edmondson III) upon histological examination.

\section{Discussion}

In Japan, the shortage of donors for liver transplantation is a major obstacle to the treatment of $\mathrm{HCC}$, thus hepatic resection is often performed as curative therapy $(4,5)$. FDG-PET/CT is a functional imaging modality that is used to measure the glucose metabolism of malignant tumors, although its clinical efficacy has not been established. The ability of PET to detect $\mathrm{HCC}$ in the liver was found to be less effective than that of contrast enhanced CT (14). On the other hand, Yoon et al (15) and Sugiyama et al (16) reported that PET is useful for the screening of extrahepatic metastasis from HCC. Recently, the usefulness of FDG-PET for predicting HCC recurrence following liver transplantation was proposed $(17,18)$. However, few reports have described FDG-PET as useful for predicting prognosis after resection $(1,2)$. Kawamura et al found that even in patients diagnosed in the early phase of HCC, a high R-SUV value among other prognostic scores may indicate poor prognosis or the need for radical treatment (3). The present results are similar to past reports, which showed that a high R-SUV value is capable of predicting early recurrence after resection, and that the relationship between a high R-SUV and pathological malignant potential is associated with positive findings for im or vp (19), higher Edmondson grade and worse gross type $(11,12)$ in resected specimens. Since the average R-SUV of Edmondson I was $<1.5$, we set 1.5 as the cut off; this cut off value predicted the early recurrence of $\mathrm{HCC}$.

Full body scanning with PET/CT is useful for the screening of extrahepatic metastasis and staging in patients with large HCC (15). An FDG-PET/CT examination is non-invasive and useful for predicting the malignant pathological potential of $\mathrm{HCC}$ before resection without the need for a biopsy. However, patients with high R-SUV values must be followed carefully with imaging modalities after resection.
In conclusion, we found that HCC patients with a high R-SUV value $(\geq 1.5)$ had an elevated risk of early recurrence after resection, while R-SUV was also shown to be related with pathological findings. Thus, R-SUV is proposed as a useful predictive marker for the early recurrence of HCC before surgical resection.

\section{References}

1. Shiomi S, Nishiguchi S, Ishizu $\mathrm{H}$, et al: Usefulness of positron emission tomography with fluorine-18-fluorodenoxyglucose for predicting outcome in patients with hepatocellular carcinoma. Am J Gastroenterol 96: 1877-1880, 2001.

2. Hatano E, Ikai I, Higashi T, et al: Preoperative positron emission tomography with fluorine-18-fluorodeoxyglucose in predictive of prognosis in patients with hepatocellular carcinoma after resection. World J Surg 30: 1736-1741, 2006.

3. Kawamura E, Habu D, Ohfuji S, et al: Clinical role of FDG-PET for HCC: relationship of glucose metabolic indicator to Japan Integrated Staging (JIS) score. Hepatogastroenterology 55: 582-586, 2008.

4. Arii S, Yamaoka Y, Futagawa S, et al: Results of surgical and nonsurgical treatment for small-sized hepatocellular carcinomas: a retrospective and nationwide survey in Japan. The Liver Cancer Study Group of Japan. Hepatology 32: 1224-1229, 2000.

5. Ikai I, Arii S, Kojiro M, et al: Reevaluation of prognostic factors for survival after liver resection in patients with hepatocellular carcinoma in a Japanese nationwide survey. Cancer 101: 796-802, 2004.

6. Arii S, Tanaka J, Yamazoe Y, et al: Predictive factors for intrahepatic recurrence of hepatocellular carcinoma after partial hepatectomy. Cancer 69: 913-919, 1992.

7. Masuda T, Beppu T, Horino K, et al: Preoperative tumor marker doubling time is a useful predictor of recurrence and prognosis after hepatic resection of hepatocellular carcinoma. J Surg Oncol: Nov, 24, 2009 (E-pub ahead of print).

8. Komura T, Mizukoshi E, Kita Y, et al: Impact of diabetes on recurrence of hepatocellular carcinoma after surgical treatment in patients with viral hepatitis. Am J Gastroenterol 102: 1939-1946, 2007.

9. Takuma Y, Nouso K, Makino Y, et al: Hepatic steatosis correlates with the postoperative recurrence of hepatitis $C$ virus-associated hepatocellular carcinoma. Liver Int 27: 620-626, 2007.

10. Poon RT, Ng IO, Fan ST, et al: Clinicopathologic features of long-term survivors and disease-free survivors after resection of hepatocellular carcinoma: a study of a prospective cohort. J Clin Oncol 19: 3037-3044, 2001

11. Stroffolini T, Andreone P, Andriulli A, et al: Gross pathologic types of hepatocellular carcinoma in Italy. Oncology 56: 189-192, 1999.

12. Iguchi T, Aishima S, Sanefuji K, et al: Both fibrous capsule formation and extracapsular penetration are powerful predictors of poor survival in human hepatocellular carcinoma: a histological assessment of 365 patients in Japan. Ann Surg Oncol 16: 2539-2546, 2009.

13. Edmondson HA and Steiner PE: Primary carcinoma of the liver. A study of 100 cases among 48900 necrosis necropsies. Cancer 7: 462-503, 1954.

14. Trojan J, Schroeder O, Raedle J, et al: Fluorine-18 FDG positron emission tomography for imaging of hepatocellular carcinoma. Am J Gastroenterol 94: 3314-3319, 1999.

15. Yoon KT, Kim JK, Kim DY, et al: Role of 18F-fluorodeoxyglucose positron emission tomography in detecting extrahepatic metastasis in pretreatment staging of hepatocellular carcinoma. Oncology 72: 104-110, 2007.

16. Sugiyama M, Sakahara H, Torizuka T, et al: $18 \mathrm{~F}-\mathrm{FDG}$ PET in the detection of extrahepatic metastases from hepatocellular carcinoma. J Gastroenterol 39: 961-968, 2004.

17. Lee JW, Paeng JC, Kang KW, et al: Prediction of tumor recurrence by $18 \mathrm{~F}-\mathrm{FDG}$ PET in liver transplantation for hepatocellular carcinoma. J Nucl Med 50: 682-687, 2009.

18. Komberg A, Freesmeyer M, Barthel E, et al: 18F-FDG-uptake of hepatocellular carcinoma on PET predicts microvascular tumor invasion in liver transplant patients. Am J Transplant 9: 592-600, 2009.

19. Sumie S, Kuromatsu R, Okuda K, et al: Microvascular invasion in patients with hepatocellular carcinoma and its predictable clinicopathological factors. Ann Surg Oncol 15: 1375-1382, 2008. 